\title{
La democratización del conocimiento en nutrición clínica
}

\author{
The democratization of knowledge in clinical nutrition \\ A democratização do conhecimento em nutrição clínica
}

\author{
Diana Cárdenas ${ }^{1 *}$ \\ https://doi.org/10.35454/rncm.v2n2.001
}

La ciencia es un bien común. Sin embargo, en el acceso a los resultados científicos se encuentran múltiples barreras. La principal barrera es la económica. Por ejemplo, para acceder en Internet a un artículo publicado en una revista indexada el autor y el lector deben pagar en promedio 40 dólares. En el caso de las universidades, bibliotecas, sociedades científicas y otras instituciones académicas estas deben pagar sumas importantes por subscripciones a los grupos editoriales que monopolizan el acceso al conocimiento.

Esta situación es el reflejo de una paradoja. En la era de la información impulsada por una economía del conocimiento de dimensiones globales, y donde el acceso a Internet ha facilitado la democratización del conocimiento, las universidades no pueden acceder totalmente a su propia producción de investigación. Incluso las mejores bibliotecas de universidades líderes en investigación no pueden darse el lujo de proporcionar acceso a todo. Las revistas son demasiado costosas, aunque cada día circulen más. Las empresas editoriales han convertido la difusión del conocimiento científico en uno de los negocios más grandes y productivos: Elsevier, Springer y Taylor y Francis, controlan el 60 por ciento de las publicaciones con ganancias millonarias anuales ${ }^{(1)}$. Estas empresas se convierten en propietarias intelectuales obteniendo ganancias económicas importantes a partir del trabajo de los autores, sus instituciones y

\footnotetext{
Médico Cirujano, Universidad El Bosque. Profesora Asistente, Facultad de Medicina, Instituto de Investigación en Nutrición, Genética y Metabolismo, Universidad El Bosque, Bogotá., D.C, Colombia.

*editor-rmnc@nutriclinicacolombia.org
}

el dinero de los organismos financiadores. A los autores y las instituciones solo les queda el prestigio de la publicación, un bien difícil de cuantificar. Lo que está en juego es, en últimas, la democratización del conocimiento científico. Según el sociólogo francés Pierre Bourdieu, el conocimiento libera de los determinismos sociales e institucionales convencionales que fundamentan las lógicas de dominación y desigualdad. Por esto, la democratización del conocimiento es fundamental para la construcción de las sociedades.

Ante la dominación y monopolio de las empresas editoriales, a inicios de la década de los 90 la comunidad académica se ha movilizado proponiendo el sistema Acceso Abierto (Open Access). Esta iniciativa conlleva a una modificación integral en el sistema de comunicación de la ciencia. Existen tres declaraciones internacionales que han definido y marcado la pauta de este modelo: las declaraciones de Budapest 2002, de Bethesda 2003 y de Berlín 2003. En 2015 la Red de Revistas Científicas de América Latina y el Caribe, España y Portugal (Redalyc) lo define como: "Movimiento internacional cuyo objetivo es que cualquier persona en el mundo, con una conexión a Internet, pueda acceder libremente sin ninguna restricción de tipo económico, técnico o legal a la información científica, académica y cultura"(2).

El Open Access es un modelo que permite el acceso y el uso de la información científica sin costo para el usuario. En pocas palabras, favorece la democratizacion del conocimiento. Aunque este modelo también ha generado controversia, de lo que se trata es de aumentar el impacto de la investigación al aumentar el acceso a la misma. En este modelo la propiedad intelectual existe, pero el uso es libre. Es decir, que el lector está autorizado a descargar, 
leer, copiar, distribuir, imprimir y enlazar a los artículos completos sin permiso previo del editor o del autor, siempre y cuando la integridad del trabajo publicado no sea alterada y sus autores sean referenciados de forma adecuada y citados cada vez que sea usada la publicación. Este modelo no implica que sea completamente gratis. Ciertas revistas cobran a los autores entre 500 y 2.500 euros por la publicación de los artículos.

Mikael Laakso et al. señalan que entre 2005 y 2009 después de una etapa llamada pionera (1993 a 1999) y una etapa de innovación (2000 a 2004), el modelo Open Access se consolidó. En estos años de "consolidación” el número de revistas y artículos ha seguido aumentando (hoy existen más de 4 millones de revistas en este sistema) y la infraestructura para el soporte de las publicaciones se desarrolló y estableció. Es así como el Open Journal System (OJS) fue desarrollado por iniciativa de The Public Knowledge Project's la cual reunió a varias universidades para desarrollar un software de código abierto (gratuito) y facilitar el Open $A c c e s s^{(3)}$. Este sistema se aplica a publicaciones revisadas por pares (peer-reviewed journals), facilitando la infraestructura técnica no solo para la presentación en línea de los artículos de la revista sino también para todo el proceso editorial. Esto incluye el envío de artículos, la revisión por pares, las decisiones editoriales y la indexación.

Este modelo cada día toma más fuerza a medida que los científicos salen de la inercia y se concientizan de que también hay revistas de excelente calidad publicadas en Open Access y que los derechos de autor y publicación son fundamentales. En Europa, donde la mayoría de los fondos para la investigación son públicos, Science Europe promueve, desde septiembre 2018, la iniciativa Plan S cuya principal reivindicación es que para 2020 las investigaciones financiadas por subvención pública deben ser publicadas en revistas o plataformas de acceso abierto ${ }^{(4)}$.

Para nosotros es un placer presentar el número cuatro $(2019 ; 2(2))$ de la Revista de Nutrición Clínica y Metabolismo, el primero que se publica en la plataforma OJS. La transferencia de la Revista a esta plataforma responde a la necesidad de cumplir con las exigencias actuales en materia de publicaciones científicas para la indexación nacional e internacional. Seguiremos publicando con el modelo Open Access para permitir el acceso total sin ningún costo al lector, a las instituciones académicas y financiadoras, a las bibliotecas y al autor. Esto se logra gracias a los esfuerzos del doctor Charles Bermúdez, presidente de la ACNC y su Junta Directiva que han conseguido los recursos necesarios para su financiación. Sea esta la oportunidad para agradecerles la confianza que han depositado en mí y que me ha permitido llevar a la Revista, dos años después, a la plataforma OJS y a su disponibilidad en diversas bases de datos.

Aunque el principal reto de este tipo de publicaciones, donde ni el lector ni el autor pagan, es la sostenibilidad. Estamos convencidos de que la ACNC se seguirá fortaleciendo y consolidando, de manera que a través de sus afiliados, actividades académicas y pauta comercial se obtengan los recursos necesarios para mantener la Revista de Metabolismo y Nutrición Clínica (RMNC) con la más alta calidad científica, elevado estándar ético y gran transparencia. Este esfuerzo es reflejo de las prioridades y de la clara política de la ACNC para desarrollar la investigación y la educación en nutrición clínica.

La indexación en otras bases de datos y la clasificación en Publindex (Índice Bibliográfico Nacional de Colombia, bajo el amparo de Colciencias) serán los retos del 2020.

Así las cosas, la plataforma OJS permitirá que que la Revista tenga una mejor visualización digital y un mejor manejo editorial a la vez que posibilitará cumplir las numerosas exigencias de Publindex y otros sistemas de Indexación.

Estamos convencidos de que la ciencia es un bien común y el acceso a los resultados científicos un derecho. En consecuencia, el equipo editorial de la Revista y la ACNC se comprometen a fomentar la democratización del conocimiento en nombre del progreso de la ciencia de la nutrición clínica.

\section{Referencias bibliográficas}

1. Willinsky J. The Nine Flavours of Open Access Scholarly Publishing. J Postgrad Med. 2003; 263-267

2. Red de Revistas Científicas de América Latina y el Caribe, España y Portugal (2015). Declaración sobre acceso abierto. México: Universidad Autónoma del Estado de México. (Consultado el 02 de agosto de 2019) disponible en: http:// www.redalyc.org/info.oa?page $=$ /acceso-abierto / declaracionoa.html

3. Open Journal System, The Public Knowledge Project. University of British Columbia. (Consultado el 1 de Julio 2019) Disponible en : http://pkp.ubc.ca.

4. Coalition-S: The Plan-S Principles. 4 de septiembre de 2018. (Consultado el 10 de Agosto 2019). Disponible en: https:// www.coalition-s.org/about/. 